\title{
Influence of Different Drying Conditions on High Strength Concrete Compressive Strength
}

\author{
M. Safan, A. Kohoutková \\ The influence of different drying conditions on the compressive strength and strength development rates of high strength concrete up to an \\ age of 28 days was evaluated. Two HSC mixes with and without silica fume addition were used to cast cubes of $10 \mathrm{~cm}$ size. The cubes were \\ stored in different drying conditions until the age of testing at 3, 7, 28 days.
}

Keywords: high strength concrete, curing conditions, silica fume, high range water reducers.

\section{Introduction}

For many years, concrete with compressive strength higher than $400 \mathrm{~kg} / \mathrm{cm}^{2}$ (40 MPa) was only available in few locations. In recent years, the applications of high strength concrete (HSC) have increased as a result of recent development in material technology and in the demand for HSC. The construction of the world tallest concrete buildings, prestressed concrete bridges, and other special structures would not have been possible without the development of HSC [1]. High strength concrete offers greater compressive strength per unit cost, weight, and volume associated with improved mechanical properties such as modulus of elasticity and tensile strength. Besides the satisfactory appearance of finished surfaces and possible reduction in the size of structural members, HSC has remarkably improved durability characteristics and thus, serviceability and maintenance problems are expected to decrease. Because of its superior characteristics, high strength concrete can be applied in a wide range of applications. It can be recommended in nuclear vessels due to its low permeability, can be applied in aggressive environments due to its high durability, and can also be a convenient design alternative in high rise buildings, prestressed bridge girders, and composite structures. Curing is a critical process for the production of high strength concrete, taking into account the low water-cement ratios usually applied in concrete mix design. Mechanical characteristics and their development rate are highly influenced by curing conditions. In the current research, crushed dolomite was used in two high strength concrete mixes with 0.0 and 10 percent silica fume addition to evaluate the influence of five different drying conditions on high strength concrete compressive strength evaluated at $3,7,28$ days.

\section{Methods of HSC Production}

High strength concrete can be produced by conventional and special techniques for production. In the former, the following considerations are usually adopted [1], [2]:

- Unless high early strength is needed, as in prestressed concrete, the most common types of portland cement (ASTM types I, II, III) can all be used to produce high strength concrete.

- Water reducers are commonly used to reduce the water-cement ratio as the most significant single factor affecting concrete strength.
- Crushed coarse aggregates with lower nominal maximum size are known to produce higher strength.

- Efficient compaction and curing are essential.

Compared to normal concrete mixtures, high strength concrete mix proportioning is a more critical process and thus, many trail batches may be required to provide data that will enable the designer to identify the optimum mix proportions. On the other hand, several exotic techniques can be applied to produce HSC. These methods include [3]:

- Modification with polymers.

- Use of active or artificial aggregate such as portland cement clinkers to enhance the paste-aggregate bond.

- Introducing a tri-axial stress state by using finely divided reinforcements such as wires, nails, steel wool high density fibers, etc.

- Increasing compaction by pressure.

- Autoclave curing.

\section{Admixtures in HSC}

Nearly all high strength concrete mixes have contained chemical admixtures. Conventional water reducers, retarders, and high range water reducers (HRWR) or superplasticizers are typical examples. Changes in the dosage and combination of these admixtures affect both the plastic and the hardened properties of concrete [1]. Also, finely divided minerals or pozzolanic admixtures such as fly ash and silica fume have been used to achieve higher strengths and better durability. Silica fume is a by-product material resulting from the reduction of high purity quartz with coal in electrical arc furnaces during the production process of ferro-silicon and silicon metal [4]. It can be obtained in a loose, condensed, and slurry form. Because of its extreme fineness (specific area of $20 \mathrm{~m}^{2} / \mathrm{g}$ ), silica fume has a high water demand and, like other pozzolanic materials, behaves more efficiently in concrete mixes having higher water-cement ratios. The action of silica fume is twofold; it reacts with free lime in cement to form a new cementitious compound, calcium silicate hydrate, and enhances the paste-aggregate bond [5], [6]. Silica fume can be applied either as an addition or as a partial replacement of cement. In the first approach, typical silica fume ratios between 5 to 15 percent by weight of cement are usually added. The increased water demand associated with silica fume addition requires the use of a HRWR to maintain 
Table 1: Drying conditions and associated average measured temperature \& relative humidity in surrounding environment

\begin{tabular}{|c|l|c|c|}
\hline Case & \multicolumn{1}{|c|}{ Drying Condition } & Relative Humidity [\%] & Temperature $\left[{ }^{\circ} \mathrm{C}\right]$ \\
\hline $\mathbf{1}$ & Water immersion & 100 & 26 \\
\hline $\mathbf{2}$ & Laboratory atmosphere & $79.0 \pm 2$ & $29.5 \pm 1$ \\
\hline $\mathbf{3}$ & Lab. Atmosphere + spraying* & \multicolumn{2}{|c|}{ Similar to case (2) } \\
\hline $\mathbf{4}$ & Direct sun + spraying * & \multicolumn{2}{|c|}{ Similar to case (5) } \\
\hline & Direct sun: & $49.0 \pm 3$ & $29.5 \pm 2$ \\
& - morning & $20.0 \pm 5$ & $39.0 \pm 1$ \\
& noon & $82.0 \pm 5$ & $24.5 \pm 1$ \\
\hline
\end{tabular}

* twice a day

Table 2: Concrete Mix Proportions [ N. M. S of C. A. (crushed dolomite) $=1 / 2$ in. and sand F. M. $=2.83$ ]

\begin{tabular}{|c|c|c|c|c|c|c|c|c|c|c|c|c|}
\hline \multirow[t]{2}{*}{ Mix } & \multicolumn{6}{|c|}{ Concrete Mix Proportions [kg/m $\left.\mathbf{m}^{3}\right]$} & \multirow{2}{*}{$\begin{array}{l}\text { Density } \\
{\left[\mathrm{kg} / \mathrm{m}^{3}\right]}\end{array}$} & \multirow[t]{2}{*}{ C. A./F. A. } & \multirow{2}{*}{$\begin{array}{l}\mathbf{S} / \mathbf{C} \\
{[\%]}\end{array}$} & \multirow{2}{*}{$\begin{array}{c}\mathbf{W} /(\mathbf{C}+\mathbf{S}) \\
{[\%]}\end{array}$} & \multirow{2}{*}{$\begin{array}{c}\mathbf{A} /(\mathbf{C}+\mathbf{S}) \\
{[\%]}\end{array}$} & \multirow{2}{*}{$\begin{array}{c}\text { Slump } \\
{[\mathrm{mm}]}\end{array}$} \\
\hline & $\mathrm{C}$ & W & F.A. & C. A. & $\mathbf{S}$ & $\mathbf{A}$ & & & & & & \\
\hline M1 & 450 & 146.9 & 728 & 1092 & 0.0 & 1338 & 2430 & 1.5 & 0.0 & 32.6 & 2.97 & 70 \\
\hline M2 & 450 & 133.7 & 720 & 1097 & 45 & 13.5 & 2441 & 1.5 & 10 & 27 & 2.73 & 55 \\
\hline
\end{tabular}

$\mathrm{C}=$ Cement

C. A. = Coarse Aggregate

$\mathrm{W}=$ Water

$\mathrm{S}=$ Silica fume

the water-cementitious ratio required to achieve the desired strength [7]. However, if more water is added to compensate the loss in slump as an alternative to the use of a HRWR, there will still be a marked increase in the compressive strength [8].

\section{Curing conditions}

Curing is the process of maintaining satisfactory moisture content and a favourable temperature in concrete during the hydration of the cementitious material so that desired properties of concrete can develop. The potential strength and durability of concrete will not fully develop, unless it is properly cured for an adequate period prior to being placed in service. At water-cement ratios below 0.4, the ultimate degree of hydration is significantly reduced if free water is not provided. Water curing will allow more efficient, although not complete hydration of the cement [9]. Kliger [10] reported that for lower water-cement ratios it is more advantageous to supply additional water during curing. For concrete mixes with water-cement ratios of 0.29 , the 28 day compressive strength of specimens cast with saturated aggregates and cured by ponding water on top was 59 to $69 \mathrm{~kg} / \mathrm{cm}^{2}$ greater than that of comparable specimens cast with dry aggregates and cured under damp burlap. Also, it was noted that while early strength is increased by elevated temperature during mixing and curing, later strengths are reduced by such temperature. However, Pfieffer [11] has demonstrated that later strengths may have only minor reductions if heat is applied after setting.

\section{Experimental work}

The current research was conducted in the strength of materials laboratory, Menofia University, Egypt. Crushed dolomite was used in two mixes with a HRWR and $0.0 \%$ and
F. A. = Fine Aggregate

$\mathrm{A}=$ Admixture (HRWR)

$10.0 \%$ silica fume addition to evaluate the effect of different drying conditions on HSC compressive strength. The drying conditions are described in Table 1 indicating the average of temperature and relative humidity in each case. A total number of 90 cubes $(100 \mathrm{~mm}$, side length) were been tested at different ages (3, 7, and 28 days) to explore the strength development rates up to an age of 28 days. Concrete mix proportions of mix M1 (0.0\% S. F.) and mix M2 (10.0\% S. F.) are reported in Table 2.

\section{Materials}

- Cement: ordinary portland cement was used. Compressive strength of mortar cubes $(70 \times 70 \times 70 \mathrm{~mm})$ measured at 3 and 7 days was 180 and $255 \mathrm{~kg} / \mathrm{cm}^{2}$, respectively.

- Aggregates: natural siliceous sand was used. The delivered sand had a fineness modulus of 2.51. Half of the sand weight was sieved using sieve No. 30. Sand retained on this sieve was blended with the rest of the sand to obtain a coarser sand with a fineness modulus of 2.83 satisfying the material recommendations in [13], [14] to achieve better workability and compressive strength as the fineness modulus approaches a value of 3.0. Crushed dolomite (specific gravity $=2.59$ and volume weight $=1.53 \mathrm{t} / \mathrm{m}^{3}$ ) with a maximum nominal size of $0.5 \mathrm{in}$. $(12.5 \mathrm{~mm})$ was used as coarse aggregate. The particles were irregular, angular in shape with a relatively high percentage of flat and elongated particles, and had a granular-porous texture. Grading curves for fine and coarse graded aggregates are shown in Figures 1, 2 along with the limits according to ASTM C33-82 [12].

- Water: tap water was used for mixing and curing.

- Chemical admixtures: one type of admixture with the trade name Addecrete-BDF was used in the two mixes. The admixture produced by Modern Construction Chemicals, 
Cairo, Egypt is classified as a high range water reducer meeting the requirements of ASTM C494 (type A, F). The admixture is a brown liquid with $1.165 \mathrm{~kg} / \mathrm{l}$ density at $20{ }^{\circ} \mathrm{C}$.

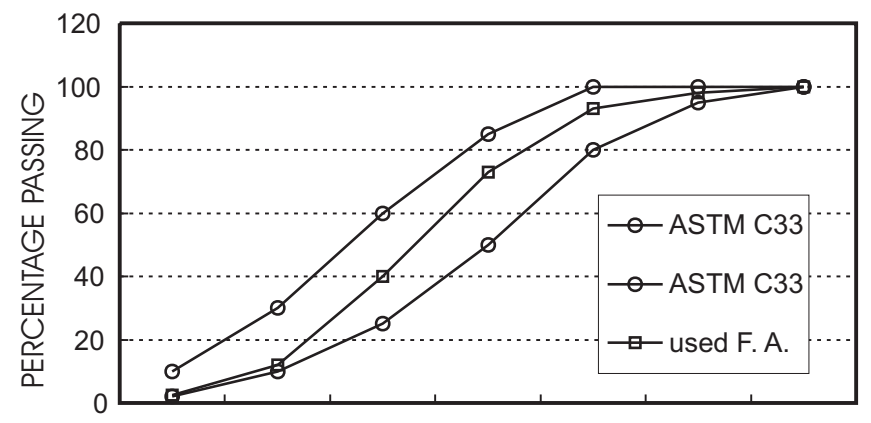

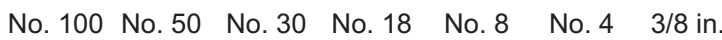
SIEVE SIZE

Fig. 1: Grading of the used sand (F. M. = 2.83)

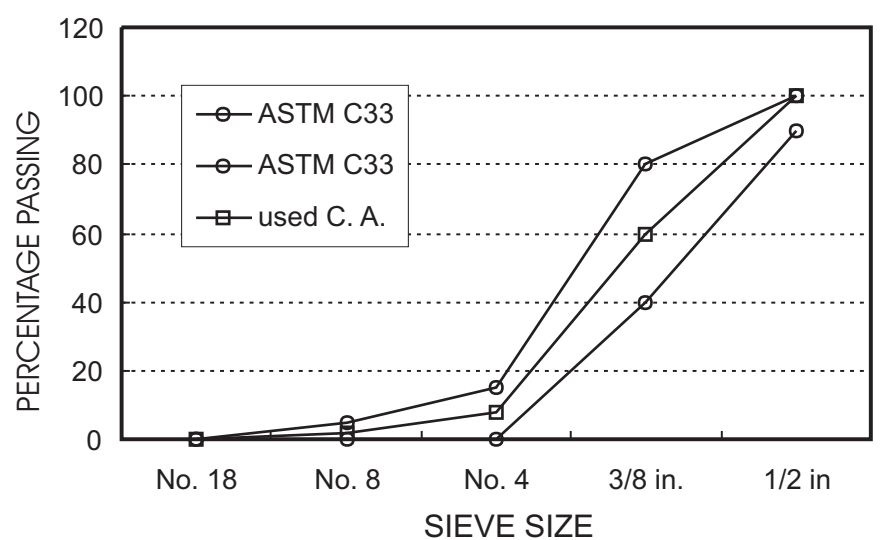

Fig. 2: Grading of crushed dolomite (M. N. S=1/2 in)
- Silica fume: silica fume provided by the Free Silicon Company, Cairo, Egypt was used in a powder form with a light gray color giving a black slurry when mixed with water. The product had a specific gravity of 2.2 , bulk density $=280 \mathrm{~kg} / \mathrm{m}^{3}$, and specific surface area $=17 \mathrm{~m}^{2} / \mathrm{g}$.

\section{- Mixing procedure:}

A 50 liter capacity mixer was used to mix batches of 20 liters needed to cast fifteen cubes. The mixer was charged with the drum at rest using the following sequence: half of the coarse graded aggregate, sand, and cement and silica fume mixed together. After charging, water was added gradually during mixing that continued for 2 minutes, the HRWR was added and mixing continued for 3 minutes to ensure adequate mixing. The concrete was charged from the mixer bowl and the slump test was then performed according to ASTM C143-78 [13]. The concrete specimens were removed from the steel molds 24 hours after adding the mixing water and stored according to the different drying schemes until the age of testing.

\section{Results}

The test results at 3, 7, and 28 days are presented in Figures 3, 5 for mix M1 and in Figures 4, 6 for mix M2. Each result represents the average of three tested cubes.

Test results for mix $M 1(0.0 \%$ S. F.): Figure 3 shows that the 28-day compressive strength for case 1 was higher than the other cases. The strength reduction increased with increased dryness of the curing environment, reaching a maximum of $15 \%$ in case (5). However, this was not the case at early ages. At an age of 3 days, case (1) did not provide the most favourable curing condition, where strength increments between 16 and 21 percent were recorded for the other cases. With the passage of time, the loss of water due to evaporation abated the hydration process resulting in the strength reduction observed at 7 and 28 days.

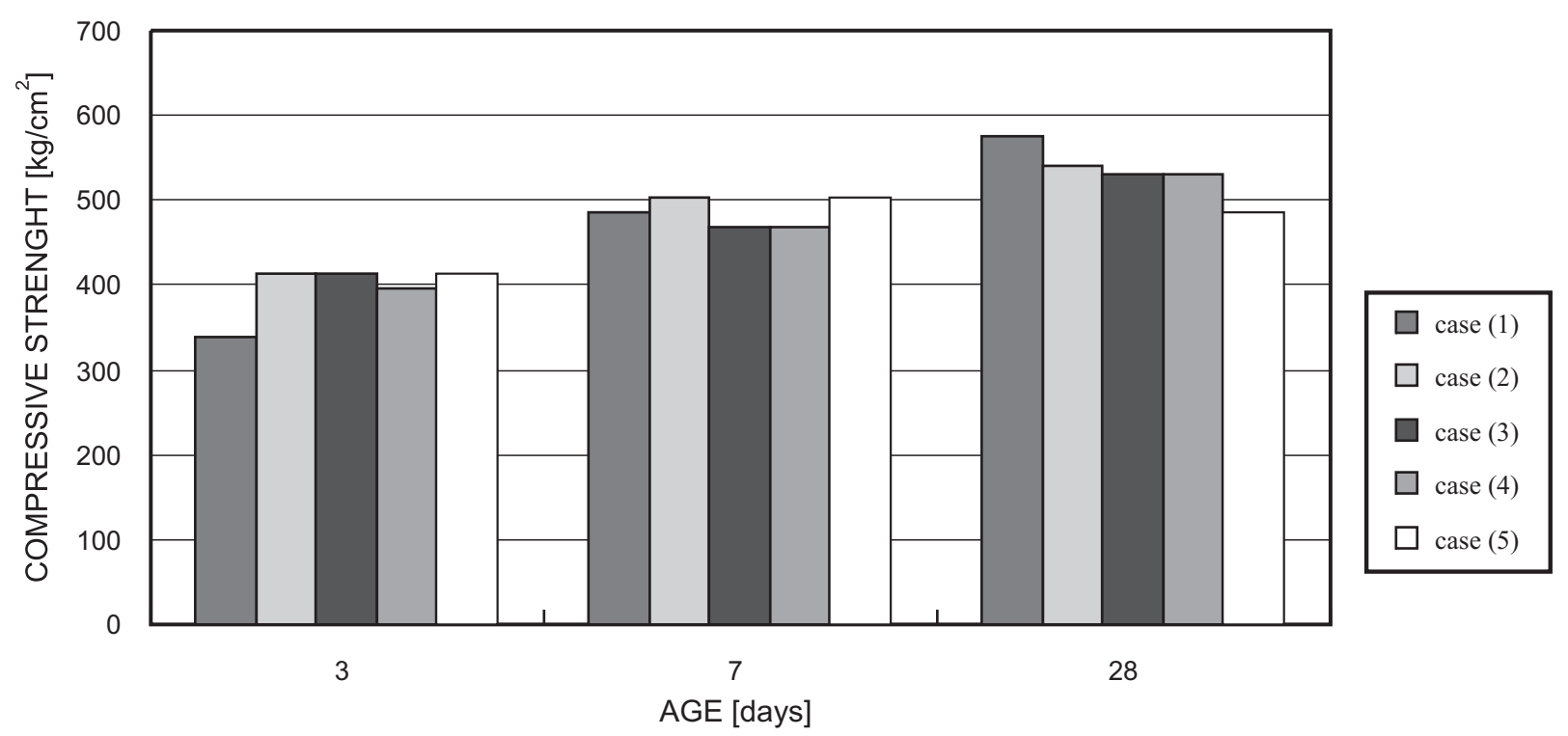

Fig. 3: Compressive strength for different drying conditions at different ages (silica fume content $=0.0$ ) 


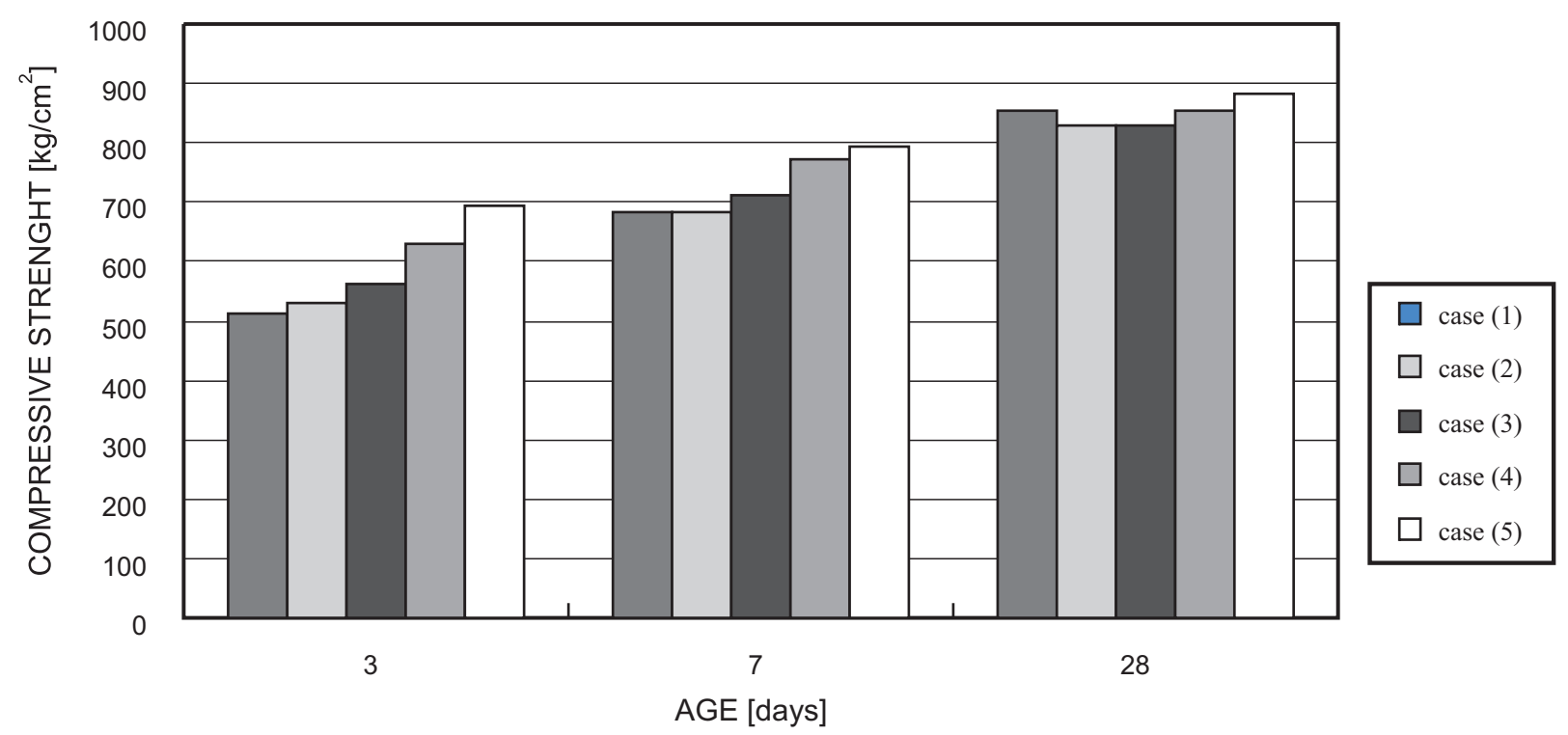

Fig. 4: Compressive strength for different drying conditions at different ages (silica fume content $=10 \%$ )

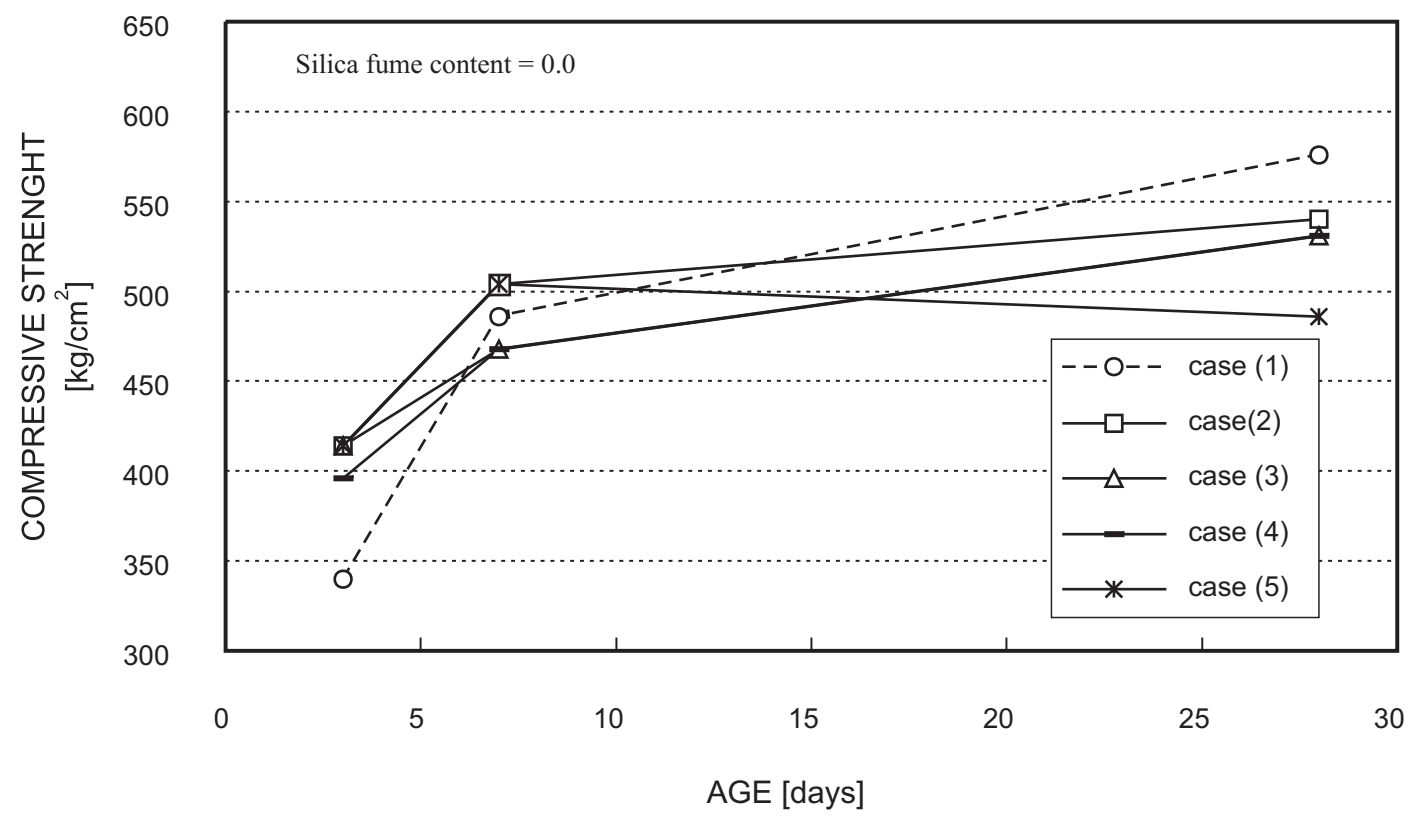

Fig. 5: Compressive strength for $100 \times 100 \times 100 \mathrm{~mm}$ concrete specimens for different curing conditions

Test results for mix M2 (10.0\% S. F.): Figure 4 shows that different drying conditions have a remarkable effect on strength especially at 3 days age. At this age, a gradual increase in strength reaching a maximum of $35 \%$ for case (5) was recorded. In case (5) a maximum temperature of $46{ }^{\circ} \mathrm{C}$ was measured at the specimen surface. This relatively high temperature simulated the cement hydration process and the pozzolanic reaction of silica fume, resulting in a remarkable strength increase. This phenomenon was also observed at later ages of 7 and 28 days. Because of its low permeability, silica fume concrete specimens kept a moisture level sufficient for the hydration process to proceed efficiently even after 28 days in a dry environment. Figures 5, 6 show the compressive strength development at different ages, indicating that case 1 provided better rates of strength gain than any other curing conditions.

\section{Conclusions}

Concrete specimens (cubes $100 \times 100 \times 100 \mathrm{~mm})$ were cured in different drying conditions (water immersion, laboratory atmosphere, laboratory atmosphere and spraying, direct sun and spraying, and direct sun). The specimens were tested at 3, 7, and 28 days. The trend according to which the compressive strength was affected by drying condition varied at different ages. It is recommended that testing should 


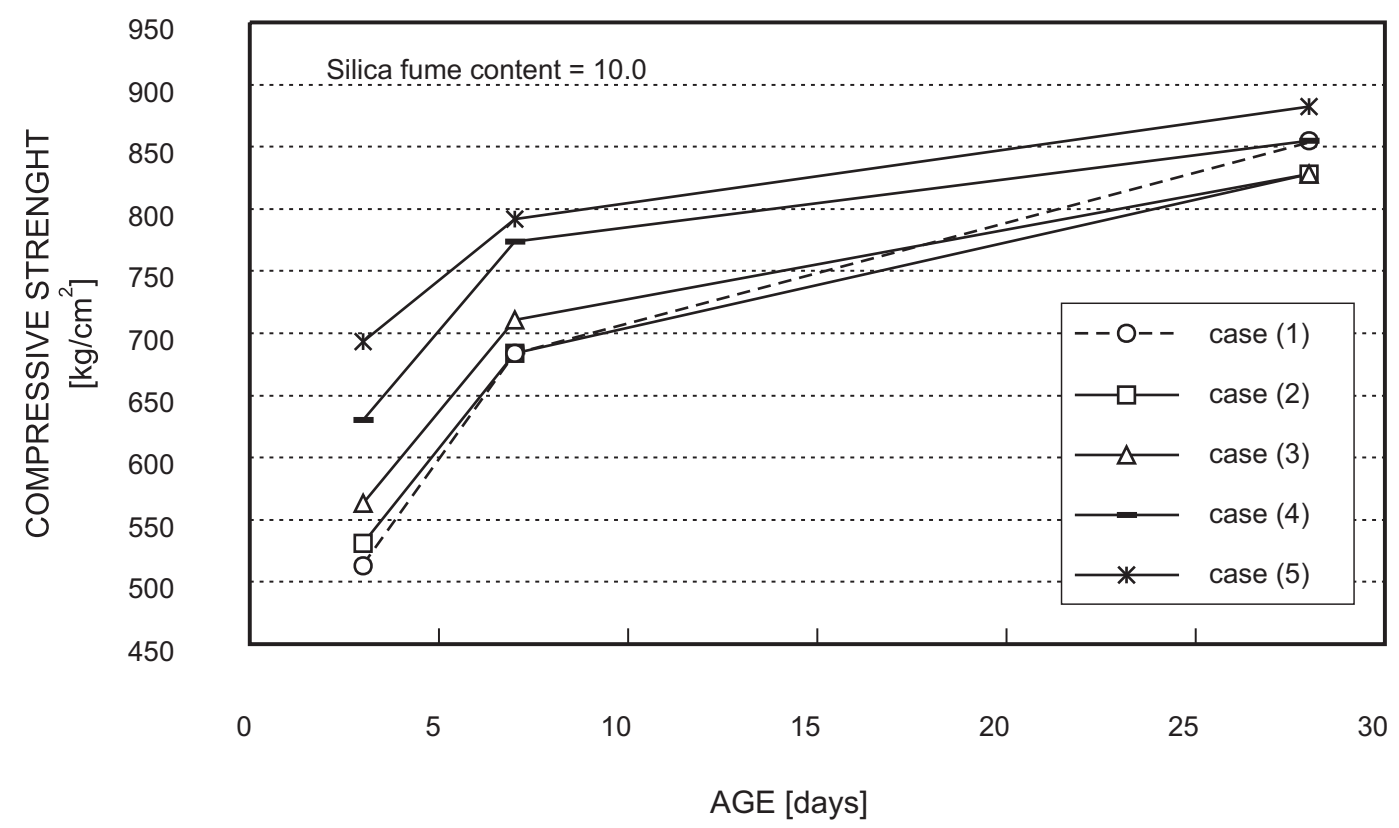

Fig. 6: Compressive strength for $100 \times 100 \times 100 \mathrm{~mm}$ concrete specimens for different curing conditions

extend in time and for different specimen sizes to provide broader understanding of the behaviour trend. However, the following conclusions could be drawn:

- High strength concrete specimens with 10 percent silica fume addition were more sensitive to drying conditions than those with zero silica fume content.

- The compressive strength of silica fume concrete specimens increased as the curing environment temperature increased. This effect was more obvious at early ages and decreased with the passage of time.

- Because of its low permeability, silica fume concrete kept a moisture content level that was sufficient for the hydration process to proceed efficiently even after 28 days in a dry environment.

- Continuously water-cured concrete specimens provided a better rate of strength development compared to other curing conditions.

\section{References}

[1] State-of-the art report on high strength concrete. ACI Committee 363 R-1984

[2] Macinnis, C., Thomson, D. V.: Special techniques for producing high strength concrete. ACI Journal, Vol. 67, No. 12/1970, pp. 996-1002

[3] Duriez, M.: Methods of achieving high strength concrete. ACI Journal, Vol. 64, No. 1/1967, pp. 45-48

[4] High strength concrete. Manual of Concrete Materials Aggregates, National Crushed Stone association, Washington, D. C., January 1975, p. 16

[5] Howard, N. L., Leatham, D. M.: The production and delivery of high strength concrete. Concrete International, April 1989, pp. 26-30
[6] Rosenberg, A. M., Gaidis, J. M.: A new mineral admixture for high strength concrete. Concrete International, April 1989, pp. 31-36

[7] Luciano, J. J., Nami, C. K.: A novel approach to developing high strength concrete. Concrete International, May 1991, pp. 25-29

[8] Malhotra, V. M., Carette, G. G.: Silica fume concrete properties: applications and limitations. Concrete International, May 1983, pp. 40-46

[9] Neville, A. M.: Properties of concrete. $3^{\text {rd }}$ Edition, Pitman Publishing Limited, London, 1981, pp. 779

[10] Kliger, P.: Early high strength concrete for prestressing. World Conference on Prestressed Concrete, San Francisco, 1957, pp. A5 (1-14)

[11] Pfieffer, D. W., Landgreen, J. R.: Energy efficient accelerated curing of concrete: a laboratory study for plant-produced prestressed concrete. Technical Report No. 1, Prestressed Concrete Institute, Chicago, December 1981

[12] ASTM C33 - 82: Specification for concrete aggregates.

[13] ASTM C143 - 78: Specification for ordinary portland cement.

Eng. Mohamed Safan, MSc

phone: +420224354620

e-mail: msafan@beton.fsv.cvut.cz

Ing. Alena Kohoutková, CSc.

phone: +420224353740

e-mail: akohout@fsv.cvut.cz

Dept. of Concrete Structures \& Bridges

Czech Technical University in Prague

Faculty of Civil Engineering

Thákurova 7, 16629 Praha 6, Czech Republic 